\title{
PROUNI: democratização do acesso às Instituições de Ensino Superior?*
}

\section{PROUNI: democratization of the access to Higher Education Institutions?}

\author{
Afrânio Mendes Catani* ${ }^{* *}$ \\ Ana Paula $\mathrm{Hey}^{* * *}$ \\ Renato de Sousa Porto Gilioli*****
}

\begin{abstract}
RESUMO
O objetivo do artigo é discutir em que medida o Prouni é um instrumento de democratização da educação superior no Brasil ou um mero programa de estímulo à expansão das Instituições de Ensino Superior (IES) privadas. Analisaremos a trajetória desse programa social desde a primeira proposta apresentada até a lei que o sancionou (janeiro de 2005), bem como os desenvolvimentos posteriores a ela. Nesse processo, o governo Lula concedeu a maioria das reivindicações do lobby das IES privadas. Apesar de induzi-las a oferecer bolsas a estudantes de baixa renda em troca de isenções fiscais, o Prouni prioriza o acesso desses estudantes à educação superior e não sua permanência.

Palavras-chave: Prouni; educação superior; democratização; acesso; IES privadas.
\end{abstract}

\footnotetext{
ABSTRACT

The objective of this paper is to discuss if Prouni (University for all Program) is a way if democratization of higher education in Brazil or a program merely

* Somos gratos a Cristina Helena A. de Carvalho pelas sugestões.

** Professor na FE-USP e no (PROLAM-USP). Livre-Docente e pesquisador do CNPq. CNPq.

*** Pós-doutoranda em Sociologia da Educação - Unicamp. Doutora e Bolsista do

***** Mestre e doutorando na FE-USP e bolsista da CAPES.
} 
devoted to stimulate the expansion of private Institutions of Higher Education (ISEs). We will analyze the trajectory of this social program, from its first proposal to the endorsement of the law (January 2005), as well its posterior developments. In this process, Lula's government conceded to almost all of the demands of private ISEs lobby. Despite of the State induct private ISEs to offer scholarships for low-income students in change of freed incomes, Prouni focus on students's access to higher education, and not their permanency in the system.

Key-words: Prouni; higher education; democratization; access; private ISEs.

A Reforma Universitária do governo Lula envolve uma série de discussões e propostas, sendo o Programa Universidade Para Todos (Prouni) anunciado como carro-chefe na democratização da educação superior brasileira. No entanto, desde o anúncio de que o Projeto de Lei seria encaminhado ao Parlamento (13.05.2004) até a versão definitiva da Lei $\mathrm{n}^{\circ} 11.096$ (13.01.2005), o Programa sofreu diversas alterações, influenciadas pelas IES particulares e beneficentes. Assim, o parco teor cidadão do Prouni, manifesto quando do lançamento da proposta, foi ainda mais tolhido, pois os benefícios e sua amplitude se reduziram. Representou, também, um estímulo à ampliação das IES privadas. Para analisar como o Programa se estruturou e em que medida pode ser considerado um instrumento de democratização da educação superior, levantaremos sua trajetória desde o projeto, a aprovação da lei e seu desenvolvimento nos dois primeiros anos, enfocando as relações entre governo e mantenedoras das IES. ${ }^{1}$

Além do Prouni, a referida Reforma Universitária conta com medidas tais como a ampliação das universidades federais e instituição de cotas para alunos da rede pública (com "subcotas" para negros e indígenas) em IES federais. Em suma, o Prouni promove uma política pública de acesso à educação superior, pouco se preocupando com a permanência do estudante, elemento fundamental para sua democratização. Orienta-se pela concepção de assistência social, oferecendo benefícios e não direitos aos bolsistas. Os cursos superiores ofertados nas IES privadas e filantrópicas são, em sua maioria, de qualidade questionável e voltados às demandas imediatas do mercado.

${ }^{1}$ Sobre o primeiro ano do Prouni, ver Catani; Gilioli, 2005. O presente artigo retoma grande parte das discussões ali presentes a atualiza os rumos adotados pela ação governamental nesse domínio. 
Um dos primeiros passos da Reforma Universitária "seria a edição de medidas que, a um só tempo, suprissem a necessidade de ampliação da rede de ensino superior e não implicassem gastos para a União" (MANCEBO, 2004, p. 80). O princípio do Prouni segue essa orientação: promove o acesso à educação superior com baixo custo para o governo, isto é, uma engenharia administrativa que equilibra impacto popular, atendimento às demandas do setor privado e regulagem das contas do Estado, cumprindo a meta do Plano Nacional de Educação (PNE - Lei $n^{\circ}$ 10.172/2001) de aumentar a proporção de jovens de 18 a 24 anos matriculados em curso superior para $30 \%$ até 2010. Pretende, ainda, atender ao aumento da demanda por acesso à educação superior, valendo-se da alta ociosidade do ensino superior privado (35\% das vagas em 2002, 42\% em 2003 e $49,5 \%$ em 2004).

Entretanto, o discurso fundamentado na meta do PNE "encobre a pressão das associações representativas dos interesses do segmento privado, justificada pelo alto grau de vagas ociosas" (CARVALHO; LOPREATO, 2005, p. 94). Os autores indicam que a principal orientação do governo na engenharia financeira do Prouni é a manutenção de uma política fiscal baseada na fixação de um valor de superávit primário. Daí a restrição de políticas públicas de maior custo para o Orçamento da União, tais como o investimento maciço nas universidades públicas. O Prouni seria um exemplo, dentre outros, do esforço em gastar menos para vender a imagem aos investidores externos de que a dívida do país é sustentável e de que não haverá calote. "Essa interpretação da política fiscal foi definitivamente implantada no Brasil após o acordo com o FMI em 1998" (CARVALHO; LOPREATO, 2005, p. 95).

O MEC pretendia instituir o Prouni por meio de Medida Provisória. No entanto, a decisão do governo foi encaminhar Projeto de Lei (PL) ao Congresso em maio de 2004. Inicialmente, o PL previa apenas bolsas de estudo integrais concedidas a "brasileiros não portadores de diploma de curso superior e cuja renda familiar não exceda a um salário mínimo per capita" (BRASIL. MEC, 2004, Art. $1^{\circ}, \S 1^{\circ}$ ). As bolsas atenderiam a cerca de 80 mil alunos, sendo destinadas apenas a concluintes do ensino médio em escolas públicas e à formação de professores da rede pública em cursos de licenciatura ou pedagogia. Os critérios para selecionar os beneficiários foram dois: a nota e o perfil socioeconômico do estudante no Exame Nacional do Ensino Médio (Enem), com exceção para os professores da rede pública. Os ingressantes em nível superior através do Prouni seriam dispensados do processo seletivo específico das instituições privadas. O pro- 
grama destacou-se por incluir políticas afirmativas, por meio da oferta de bolsas aos autodeclarados negros e indígenas.

As IES não-beneficentes (com ou sem fins lucrativos) ofereceriam uma bolsa para cada nove alunos regularmente matriculados em cursos efetivamente instalados (Art. $5^{\circ}$, caput). Já as beneficentes deveriam destinar uma bolsa integral para cada quatro alunos de cursos de graduação ou seqüencial de formação específica (Art. 11). Em contrapartida, ficariam isentas do Imposto de Renda das Pessoas Jurídicas (IRPJ), da Contribuição Social sobre o Lucro Líquido (CSLL), da Contribuição Social para Financiamento da Seguridade Social (Cofins) e da Contribuição para o Programa de Integração Social (PIS). A renúncia fiscal em 2005 foi de 92 milhões de reais. Desde o fim dos anos 60, "o governo militar valeu-se intensamente da política de incentivos e isenções fiscais como forma de apoiar a atuação privada no projeto de desenvolvimento nacional, beneficiando ampla gama de setores em diferentes áreas" (CARVALHO; LOPREATO, 2005, p. 99). O crescimento das IES privadas dependeu, em grande medida, desse incentivo. A Constituição Federal de 1967 "determinava a não incidência de impostos sobre a renda, o patrimônio e os serviços dos estabelecimentos de ensino de qualquer natureza", com o que "as organizações privadas de ensino superior gozaram do privilégio, desde a sua criação, de imunidade fiscal, não recolhendo aos cofres públicos a receita tributária devida" (CARVALHO; LOPREATO, 2005, p. 99). Esse instrumento mostrou-se fundamental "para o crescimento intensivo dessas estruturas na prosperidade econômica, garantindo (...) a continuidade da atividade da empresa educacional no período de crise por meio da redução do impacto sobre custos e despesas" (CARVAlHo; LOPREATO, 2005).

Com a LDB/1996, as IES privadas, que não pagavam IRPJ, ISS e IPTU, foram divididas em com fins lucrativos e sem fins lucrativos. "As primeiras deixaram de se beneficiar diretamente de recursos públicos e indiretamente da renúncia fiscal, ao passo que as demais permaneceram imunes ou isentas à incidência tributária" (CARVAlHo; LOPREATO, 2005, p. 101). Nesse sentido, o Prouni representa a retomada de uma tradição de políticas de renúncia fiscal que mais beneficiam o setor privado do que induzem políticas públicas democratizantes.

No PL do Prouni, o vínculo das IES valeria por dez anos, renovável por iguais períodos. Não poderiam participar instituições com desempenho insuficiente no Sistema Nacional de Avaliação de Educação Superior (SINAES) por dois anos consecutivos ou três intercalados, no período de cinco anos (Art. $\left.7^{\circ}, \S 4^{\circ}\right)$. Na MP e na Lei, o desvinculamento foi abranda- 
do para desempenho insuficiente no SINAES por três anos seguidos. Enquanto o PL condicionava a participação das IES no Financiamento ao Estudante do Ensino Superior (FIES) à adesão ao Prouni, na MP essa restrição foi suavizada: o acesso ao FIES passou a ser prioritário para as IES aderentes ao Prouni (BRASIL. PODER EXeCuTIVo, 2004, Art. 13). As IES que descumprissem as regras do Prouni seriam multadas em até $1 \%$ do faturamento anual (punição retirada da MP e da Lei), teriam que restituir a porcentagem de 10\% (IES não-beneficentes) e 20\% (IES beneficentes) de bolsas integrais caso ficassem abaixo do mínimo e seriam desvinculadas do Prouni em caso de reincidência.

\section{A desfiguração do projeto inicial}

Quando o PL chegou ao Congresso, as mantenedoras propuseram modificações no Prouni, sendo representadas principalmente pela Associação Nacional das Universidades Particulares (ANUP), pela Associação Brasileira de Mantenedoras de Ensino Superior (Abmes) e pelo Sindicato das Entidades Mantenedoras de Estabelecimentos de Ensino Superior no Estado de São Paulo (Semesp). Sugeriram a desobrigação das filantrópicas destinarem $20 \%$ da gratuidade em bolsas integrais, queriam incluir bolsas parciais, ampliar a faixa de renda familiar per capita de um para três s.m. e exigir processos seletivos nas instituições afora o Enem. As IES com fins lucrativos queriam reservar apenas $5 \%$ de suas vagas aos alunos carentes, não oferecer bolsas integrais e conceder bolsas parciais de $20 \%$ a $80 \%$ (o ESTADO DE S. PAULO, 2004). O Semesp reivindicava bolsas parciais de 50\%, logo aceitas pelo relator da comissão que analisou o PL, deputado Irineu Colombo (PT-PR).

Diante de tais propostas, o Prouni começava a ser desfigurado. Na melhor das hipóteses, constituiu-se em um programa assistencialista que prioriza apenas o acesso do estudante ao ensino superior. Até mesmo os representantes das mantenedoras levantaram a questão da permanência: "Um dos pontos criticados por representantes das instituições e dos estudantes [no PL] é a renda per capita exigida, de um s.m., o que impossibilitaria o estudante de se manter na universidade" (TAKAHASHI, 2004). Contudo, preocupavam-se porque bolsistas parciais de renda muito baixa não 
resolveriam o problema crônico da evasão escolar nas IES privadas. Daí a sugestão de ampliar a renda exigida para três s.m. A essas reivindicações somaram-se mais duas apresentadas pelo Semesp (ambas atendidas desde a MP): participação de estudantes que tinham cursado o ensino médio privado como bolsistas integrais e inclusão de uma regra de transição tributária para as IES "sem fins" se transformarem em "com fins" lucrativos. Havia, também, a pressão das universidades filantrópicas contra a conversão dos $20 \%$ de gratuidade exclusivamente em bolsas integrais.

O PL recebeu 292 propostas de emenda, a maioria beneficiando as mantenedoras. Dentre as aceitas pelo relator do PL na Câmara até 12.08.2004, permitiu-se que as IES filantrópicas destinassem meia-bolsa (50\% do valor do curso) aos estudantes, diferentemente do previsto no PL. Para as beneficentes, a exigência de bolsas integrais caiu de $20 \%$ para $10 \%$. Já a faixa de rendimento dos bolsistas integrais subiu de um para 1,5 s.m. O Semesp ainda reivindicava inclusão de "bolsa parcial de um terço [e] a prestação de serviços comunitários para os alunos beneficiados" (FOLHA ONLINE, 2004a).

Em 25.08.2004, a votação na Câmara já fora adiada pela segunda vez. Acuado, o governo anunciara no dia anterior que mais de 30 IES já teriam aderido ao Prouni. Ao invés de demonstrar força, provocou rejeição ao relatório apresentado pelo deputado Colombo. Diante da falta de acordo, o governo passou a negociar diretamente com as mantenedoras até obter aprovação majoritária do setor e editou a Medida Provisória (MP) do Prouni.

\section{Diálogo "democrático" apenas com as IES privadas}

O texto da MP no 213 (13.09.2004) do Prouni adotou quase todas as propostas das IES privadas. O caput do Art. $1^{\circ}$ previa a concessão de bolsas de estudo integrais e bolsas de estudo parciais de 50\% (BRAsIL. PODER EXECUTIVO, 2004). Ainda não fora atendida a reivindicação de bolsas parciais de $30 \%$ ou $20 \%$, mas a meia-bolsa $(50 \%)$ já representava vitória do setor. As rendas limite foram ampliadas de um para 1,5 s.m. (bolsa integral) e criou-se o limite de $3 \mathrm{~s}$. m. (bolsa parcial). Foram acrescentados alunos com necessidades especiais como destinatários e, conforme demanda do Semesp, aqueles que cursaram todo o ensino médio como bolsistas integrais em instituições privadas. 
O Art. $3^{\circ}$ introduziu a "seleção" interna na IES após a "pré-seleção" do Enem, o que teve impacto na distribuição de bolsas. O exemplo da PUC Minas é significativo: em 2005, apenas 65,7\% dos candidatos pré-selecionados ao Prouni foram aprovados pela universidade; $21,6 \%$ não compareceram na seleção interna e 12,8\% foram reprovados. Dos aprovados, 17,8\% não se matricularam - motivos: percentual da bolsa parcial insuficiente; aprovação em instituição pública; desinteresse pelo curso selecionado (o candidato pode fazer até cinco opções de curso) -, reduzindo a quantidade de bolsistas (PUC MINAS, 2006).

Na MP, as IES não beneficentes ofereceriam uma bolsa integral "para cada nove estudantes pagantes regularmente matriculados em cursos efetivamente nela instalados" (Art. $5^{\circ}$, caput). Diferentemente do PL, há o termo "estudantes pagantes" ao invés de "alunos", incidindo a proporção de beneficiários sobre a receita das mensalidades e não sobre o número de matriculados. Metade dos 10\% de bolsas integrais das IES não-beneficentes poderia ser convertida em meias-bolsas, reduzindo o parco caráter democratizante do Prouni. A limitação das meias-bolsas reside no fato de que, caso seus beneficiários não paguem em dia a parte que lhes cabe, não podem renovar matrícula no semestre ou ano seguinte do curso (Art. $5^{\circ}$, Lei 9.870/99). Assim, a possibilidade de evasão aumenta. Por isso, o Prouni institui uma política de acesso, mas não de permanência na educação superior, na qual o estudante é tratado como consumidor e não como cidadão.

As IES beneficentes também ganharam com a edição da MP, pois a obrigatoriedade de bolsas integrais nessas instituições foi reduzida de $20 \%$ (redação do PL) para 10\% da receita bruta, menor que o percentual de bolsas integrais oferecido por algumas PUCs antes do Prouni. Os $10 \%$ restantes da gratuidade deveriam compor bolsas parciais de $50 \%$ e assistência social $\left(\right.$ Art. $9^{\circ}, \S 2^{\circ}$ ), reivindicação do setor, que não queria parte da gratuidade das bolsas integrais em suas pouco fiscalizadas ações beneficentes.

Outro ponto polêmico foi o Art. 12. As IES sem fins lucrativos ganham privilégios convertendo-se em com fins lucrativos: "passarão a pagar a quota patronal para a previdência social de forma gradual, durante (...) cinco anos, na razão de $20 \%$ do valor devido a cada ano, cumulativamente, até atingir o valor integral das contribuições devidas" (BRASIL. PODER EXECUTIVo, 2004). A transformação de uma entidade sem fins lucrativos fere o Art. 213 da CF-1988: para ela, uma escola comunitária, confessional ou filantrópica só pode receber recursos públicos se, ao encerrar suas atividades, destinar o patrimônio a outra congênere ou ao setor público (BRASIL, 
2003, p. 69). A Universidade Estácio de Sá é um exemplo: maior IES privada do país (mais de 100 mil alunos), mudou seu estatuto de filantrópica para com fins lucrativos. Além das isenções adquiridas, pagará o valor integral da cota patronal do INSS (Instituto Nacional do Seguro Social) só em 2010 (FOLHA ONLINE, 2004c). Com a mudança, não precisa oferecer $20 \%$ de gratuidade, apenas $10 \%$ (5\% em bolsas integrais).

Enquanto cedia às IES e era elogiado pelas mantenedoras, o MEC restringia-se a "esclarecer dúvidas sobre a Medida Provisória" e a "discutir o que pode vir a ser um sistema de controle do programa" com o Movimento dos Sem Universidade - MSU (Folha DE S. PAUlo, 2004a). A fiscalização foi prevista para começar apenas quando o SINAES estiver totalmente implementado, o que o MEC estima para 2008. Antes disso, a idéia era "realizar convênios entre o Ministério e as universidades federais e estaduais para que elas possam verificar as condições das instituições privadas e enviar essas informações para análise do MEC" (FOLHA ONLINE, 2004b). Entretanto, tal solução não foi adotada. Ao contrário: em 30.01.2006, o MEC criou, tardiamente, a Comissão Nacional de Acompanhamento e Controle do Programa Universidade para Todos (CONAP), "órgão colegiado com atribuições consultivas, vinculado à Secretaria de Educação Superior" (BRASIL. MEC, 2006). O órgão é controlado, predominantemente, pela iniciativa privada: dois estudantes do ensino médio e dois do superior privado (indicados pela UNE e UBES), dois professores do ensino superior privado (apontados por sindicatos docentes), além de dois representantes das mantenedoras (designados pela ABMES e pelo Conselho de Reitores de Universidades Brasileiras, CRUB), dois da "sociedade civil" e dois do MEC (BRASIL. MEC, 2006). As universidades públicas não foram representadas, favorecendo o lobby das IES privadas e dificultando o controle da qualidade dos cursos oferecidos.

A falta de controle sobre o Prouni é tanta que muitos bolsistas perderam o ano: suas turmas foram fechadas pelas IES. Embora tenham a obrigação de destinar esses alunos a outras IES, para que eles não percam o semestre, o ano ou mesmo o curso, a fiscalização tem sido débil. Chega-se ao ponto de os bolsistas terem de se reinscrever em nova seleção do Prouni após não conseguirem realocação em outras IES (FOLHA DE S. PAULO, 2006). 


\section{A MP no Parlamento em fins de 2004: outra ofensiva do setor privado}

A MP do Prouni sofreu, ainda, outras mudanças em relação à sua redação original para ser aprovada em primeira votação na Câmara dos Deputados (01.12.2004). A principal estabeleceu que as IES não-beneficentes (com ou sem fins lucrativos) destinariam apenas 7,14\% (a redação referia-se a uma bolsa integral para cada 13 alunos pagantes) de suas vagas aos beneficiários (a MP estabelecia 10\%). Em relação às IES com fins lucrativos, a exigência de ofertar bolsas integrais caíra para a proporção de apenas um beneficiário para cada 28 alunos pagantes $(3,44 \%)$. Apenas os $20 \%$ de gratuidade (metade em bolsas integrais e o restante em meiasbolsas e assistência social) das beneficentes foi mantida. A redução da proporção de bolsistas de $10 \%$ para $7 \%$ foi uma grande derrota do governo. Pouco depois, os senadores aprovaram a MP do Prouni (16.12.2004). A negociação governo-oposição levou a um acordo que deixou o porcentual de bolsistas nem em 7\% (Câmara) nem em 10\% (MP), mas em 8,5\% a partir de 2006. Modificada pelo Senado, a MP retornou à Câmara para votação final seis dias depois, confirmando o texto.

Os critérios iniciais para selecionar os beneficiários no Prouni continuaram sendo a nota (mínimo 45 pontos) e a condição socioeconômica declarada no Enem. Em 2003, 1,9 milhão se inscreveram no Enem e, em 2004, mais de 1,5 milhão. Em 2005, foram quase três milhões, dos quais $25 \%$ não compareceram e 900 mil concorreram às bolsas do Prouni. A explosão da procura em 2005 foi creditada à obrigatoriedade do exame para se inscrever no Prouni. A primeira seleção ocorreu em fins de 2004 e só aceitou candidatos que fizeram o Enem em 2004. Assim, o Prouni selecionou apenas $64.982(26,62 \%)$ dos 244.088 inscritos (FOLHA DE S. PAULO, 2004b). Dos 64.982, 20.967 entraram nas cotas destinadas a negros e indígenas. A segunda fase de inscrições aceitou alunos que fizeram o Enem em 2002 e 2003 para preencher as vagas restantes. O MEC contabilizou 154.944 candidatos para as 47.434 bolsas remanescentes (23.321 integrais e 24.113 parciais de $50 \%$ ) em 1.135 IES.

Para enfrentar a dificuldade de preencher as vagas (em especial bolsas parciais destinadas às cotas étnicas, que tiveram baixa procura, pois a renda familiar do segmento muitas vezes não permite arcar com $50 \%$ ou $75 \%$ das mensalidades), o MEC estabeleceu que os estudantes com meia- 
bolsa teriam mais $25 \%$ do valor do curso financiados pelo FIES. Houve uma terceira fase (136.802 inscrições) para as 10.134 bolsas parciais e 6.441 integrais restantes - total de 16.575 benefícios, 12.786 dos quais prioritários para as cotas raciais. Houve, ainda, excedente de 4.939 vagas (CONSTANTino, 2005a), redistribuídas em 2 seleções ao longo de 2005. Foram preenchidas pouco mais de 112.000 vagas (72 mil em bolsas integrais), superando a expectativa inicial do governo de 70 a 80 mil beneficiários para 2005. A meta para os primeiros quatro anos de Prouni passara de cerca de 300.000 (maio/2004) para 760.000 benefícios (julho/2005).

$\mathrm{O}$ MEC informou que 95.000 bolsistas continuaram nas vagas do Prouni (UOL EDUCAÇão, 2006) em 2006 - isto é, 15\% desistiram. Quanto ao desempenho acadêmico dos beneficiários, há dados escassos. Na PUC Minas, 77,2\% dos ingressantes pelo Prouni no início de 2005 foram aprovados em todas as disciplinas, enquanto o índice geral da universidade foi 70,3\%. Quanto à evasão, o índice é similar à média geral da IES. Em 2005, a PUC Minas ofereceu 2.300 bolsas para o Prouni, "sendo uma das universidades que mais tem destinado vagas ao Programa”. Em 2006 foram apenas 1.511 (PUC MINAS, 2006).

Na seleção aos benefícios de 2006, houve 797 mil inscritos (130\% a mais do que no ano anterior, quando houve a primeira seleção) para 91.100 bolsas, preenchendo 94,4\% das vagas (FOLHA ONLINE, 2006a). Sobraram 5.100 bolsas, oferecidas na segunda seleção (a inscrição se encerrou em 14.01.2006), com o resultado divulgado 3 dias depois, restando apenas 1.071 bolsas, cerca de metade para cursos à distância (FOLHA ONLINE, 2006b). O MEC ofertará mais 40.000 vagas no $2^{\circ}$ semestre, totalizando $131.100 \mathrm{em}$ 2006.

Apesar dos números crescentes sugerirem efeito democratizante, o problema maior do Prouni é a permanência do estudante até a conclusão do curso (além da questionável qualidade das IES). O Observatório Universitário da Universidade Cândido Mendes constatou que cerca de 35\% dos alunos que estão no último ano do ensino médio ou que já o concluíram (3,7 milhões num total de 10,5 milhões) "vêm de famílias em que a renda média nem sequer é suficiente para comprar eletrodomésticos de primeira necessidade, como geladeiras, ou que comprometem mais de $40 \%$ do orçamento familiar com aluguel" (GOIs, 2004a). Além disso, uma família com renda de $\mathrm{R} \$ 1.000$ a $\mathrm{R} \$ 1.200$ "consome $82 \%$ de seus recursos com despesas essenciais como alimentação, habitação, transporte, higiene, saúde e vestuário. Em famílias no extremo mais pobre (renda mensal inferior a R\$ 400), o orçamento familiar é insuficiente para cobrir essas despesas básicas" (GOIs, 2004a). 
Parte da resposta a tais problemas poderia estar no projeto do MEC de concessão de bolsas-permanência a esses estudantes. O Ministro Tarso Genro falava em 60 a 80 mil bolsas-permanência de um s.m. para estudantes carentes do Prouni em agosto de 2004 (stachuK, 2004). Mas elas foram "esquecidas" por mais de um ano: "a Secretaria [de Educação Superior do MEC] está discutindo com as instituições privadas maneiras de assegurar a permanência desses alunos, mas (...) essa iniciativa deve partir também das universidades" (GOIS, 2004b). Em suma, a questão da permanência, fator essencial das políticas de educação superior, pretendia ser simplesmente delegada à iniciativa privada.

Em junho de 2005, o governo anunciava um "pacote de bondades" para a área educacional, que incluiria a criação, por meio de Medida Provisória, da bolsa-permanência do Prouni. Previa-se que apenas 4.000 estudantes com bolsas integrais seriam beneficiados (CONSTANTINO, 2005b). A Lei 11.180, Art. 11 (23.09.2005), criou a bolsa-permanência de R \$ 300,00 para bolsistas integrais do Prouni e matriculados em cursos em tempo integral. Os critérios e a fiscalização das bolsas foram regulamentados cinco meses depois - a Portaria $\mathrm{n}^{\circ} 569$ do MEC estabeleceu os cursos nos quais poderia haver beneficiários: Agronomia, Ciência da Computação, Enfermagem, Engenharias, Farmácia, Fisioterapia, Informática, Medicina, Odontologia e Veterinária, contanto que tivessem ao menos 6 semestres de duração e média mínima de 6 ou mais horas de aulas diárias.

\section{A sanção da Lei do Prouni no início de 2005}

A Lei do Prouni ( $\left.n^{\circ} 11.096 / 2005\right)$ foi sancionada pelo Presidente Lula em 13.01.2005. No Art. $1^{\circ}$ são mencionados, além de bolsas integral e parcial de $50 \%$, benefícios parciais de $25 \%$ do valor do curso. Meses antes, as IES reivindicavam bolsas parciais $30 \%$ ou $20 \%$. A proporção de bolsas integrais nas IES não-beneficentes respeitou o acordo do Senado: para 2005 foi mantido o texto da MP (um benefício para cada nove pagantes), com o acréscimo da possibilidade de desdobramento em bolsas parciais de $25 \%$. Mas de 2006 em diante o percentual foi reduzido a uma bolsa integral para o equivalente a 10,7 estudantes regularmente pagantes e devidamente matriculados ao final do correspondente período letivo anterior (Art. $5^{\circ}$, 
caput), o que equivale a 8,5\%. Para "recuperar" os $10 \%$ de bolsas (reduzidas a $8,5 \%$ no Congresso), inseriu-se punição às IES que descumprirem o percentual. Se a IES não oferecer $8,5 \%$ em bolsas integrais, terá que restabelecer essa proporção e acrescentar a ela mais 1/5 (inciso I do Art. $9^{\circ}$ ). Em suma, se se comportarem, as IES ficam com os $8,5 \%$ obtidos no Parlamento; senão, ficarão sujeitas a 10,2\%.

A MP estabelecia que as IES não-beneficentes poderiam oferecer no mínimo 5\% de bolsas integrais e converter as 5\% restantes em meiasbolsas. Para 2005, a Lei do Prouni manteve a regra. A partir de 2006, exigiu no mínimo um bolsista integral para cada 22 alunos pagantes $(4,34 \%)$. Os $4,16 \%$ restantes podem ser "fragmentados" em bolsas parciais de $50 \%$ e $25 \%$ (Art $5^{\circ}, \S 4^{\circ}$ ). O objetivo é claro: a proporção continua em $8,5 \%$, mas a quantidade de beneficiários aumenta muito. Se considerarmos a faixa de renda (até três s.m.), a probabilidade de evasão dos bolsistas parciais cresce ainda mais com bolsas de $25 \%$. Em relação às IES beneficentes, a adesão às regras do Prouni permitiu a regularização daquelas em situação ilegal nos 6 anos anteriores e a requisição da reativação da imunidade tributária (18\% sobre o lucro líquido e $2 \%$ sobre a receita bruta) perdida. Há ainda outra concessão às IES na Lei: trabalhadores (e dependentes) da IES podem ser contabilizados como beneficiários até o limite de $10 \%$ das bolsas Prouni concedidas (BRASIL. PODER LEGISLATIVo, 2005, Art. 12), reduzindo o percentual de bolsistas novos, reaproximando-o dos 7,5\% defendida pelo Semesp desde setembro de 2004.

\section{Considerações finais}

O Prouni é comumente visto como mais uma política pública, particularmente por abrigar o preceito das cotas, mas destaca-se o fato de manter um sistema de ensino nos moldes privatizantes traçados durante os anos 1990. Nesse sentido, traz uma noção falsa de democratização, pois legitima a distinção dos estudantes por camada social de acordo com o acesso aos diferentes tipos de instituições (prioridade para a inserção precária dos pobres no espaço privado), ou seja, contribui para a manutenção da estratificação social existente. O comentário do presidente da Abmes fala por si mesmo: "A proposta não saiu como pretendíamos, mas é razoável e favorece as instituições privadas" (MENA, 2004). 
A falta de mecanismos de controle democrático do Prouni reflete-se até mesmo no fato de ele não se caracterizar como uma Parceria Público Privada (PPP), solução encontrada pelo governo para lidar com a baixa capacidade de investimento decorrente da política de ajuste fiscal baseada na determinação de um valor do superávit primário. As PPPs têm vários aspectos que o Prouni não cobrou do setor privado, tais como "a exigência de licitação, a constituição de sociedade com propósito específico, a garantia de rentabilidade, a segurança de recebimento etc." (CARVALHO; LOPREATO, 2005, p. 96). "O que o Prouni faz é aumentar as isenções fiscais para IES privadas que, com poucas exceções, não prestam contas de como as usam, remuneram de forma ilegal seus sócios, não têm transparência na concessão de bolsas e maquiam balanços" (valente; Helene, 2004). É, assim, uma medida de impacto popular, privatista e de baixo custo orçamentário.

Ao invés de privilegiar as IES privadas, o governo poderia investir no setor público, capaz de democratizar a educação superior. Todavia, para cumprir a meta do PNE de ampliar de $9 \%$ para $30 \%$ a população de 18 a 24 anos no ensino superior até 2010, o MEC optou por conceder benefícios e não promover direitos. Contra a alegação do governo (HADDAD; BACHUR, 2004) de que o Prouni é complementar (e não antagônico) à universidade pública, cabe lembrar que suas bolsas contribuem "para o aumento da oferta privada nesse campo. Assim, o que está em jogo não é o 'afastamento' da ação estatal, senão sua reconfiguração quanto à oferta do ensino superior" (MANCEBO, 2004, p. 85). Afinal, "a política pública que privilegia a democratização pela via privada não encontra como principal entrave a oferta insuficiente de vagas, mas a natureza dessas vagas e/ou a capacidade dos candidatos de ocupá-las" (CARVAlHo; LOPREATO, 2005, p. 103).

Até como mera política assistencialista o Prouni é fraco, porque espera que as IES privadas "cuidem" da permanência do estudante. Abre o acesso à educação superior, mas não oferece mais do que um arremedo de cidadania de segunda classe aos contemplados. Cabe lembrar que o Prouni previa em sua primeira versão $20 \%$ das vagas de todo o enorme setor privado, percentual que despencou para ínfimos $8,5 \%$. Desse modo, a alcunha criada pelo jornalista Josias de Souza para o Prouni expressa enfaticamente a característica principal do programa (o benefício às mantenedoras): "promamata" (souZA, 2004, p. 14).

Por fim lamentamos, na qualidade de pesquisadores e analistas de políticas públicas, a pouca transparência do MEC no que se refere às informações fornecidas a respeito do Prouni. Não encontramos razão para que não seja disponibilizado o total de bolsas contratadas por IES; uma tipologia 
das IES que aderiram ao Programa; as modalidades das bolsas (integrais e parciais); o detalhamento dos cursos "disponíveis" e/ou "escolhidos"; os perfis os alunos, aí englobando dados econômicos e sociais; as taxas de evasão; o desempenho escolar dos beneficiários etc. Com essas informações básicas e após análises de algumas séries históricas, poderíamos verificar se nos encontramos diante de um efetivo instrumento (que pode vir a se constituir no futuro) de democratização da educação superior no Brasil ou de uma equação eficaz que desprestigia a esfera pública, valoriza IES privadas de qualidade duvidosa e alavanca índices estatísticos capazes de acobertar um déficit educacional que não se resolve com malabarismos fiscais.

\section{REFERÊNCIAS}

BRASIL. Constituição da República Federativa do Brasil. Constituição do Estado de São Paulo. Declaração Universal dos Direitos Humanos. São Paulo: Imprensa Oficial do Estado de São Paulo, 2003. 179 p.

BRASIL. MEC. Projeto de Lei $n^{\circ} 3.582$ - 28 mar. 2004. Dispõe sobre a instituição do Programa Universidade para Todos - PROUNI, e dá outras providências. Brasília: MEC, 2004. Disponível em: www.camara.gov.br/sileg/integras/219649.htm. Acesso em 06 jan. 2005.

Portaria $n^{\circ} 301$ - 30 jan. 2006. Dispõe sobre a Comissão Nacional de Acompanhamento e Controle do Programa Universidade para Todos - Prouni. Diário Oficial da União, Brasília, Imprensa Nacional, n. 22, seção 1, 31 jan. 2006. Disponível em: http:// prouni-inscricao.mec.gov.br/prouni/pdf/Portaria_nr_301_2006.pdf. Acesso em: 13 maio 2006.

BRASIL. PODER EXECUTIVO. Medida Provisória $n^{\circ} 213$ - 10 set. 2004. Institui o Programa Universidade para Todos - PROUNI, regula a atuação de entidades beneficentes de assistência social no ensino superior, e dá outras providências. Diário Oficial da União, 13 out. 2004. Disponível em: www.presidencia.gov.br/ccivil/_ato2004-2006/2004/ mpv/213.htm. Acesso em: 07 jan. 2005.

. Lei $n^{\circ} 11.096$ - 13 jan. 2005. Institui o Programa Universidade para Todos Prouni, regula a atuação de entidades beneficentes de assistência social no ensino superior, altera a Lei n ${ }^{\circ} 10.981$, de 9 de julho de 2004, e dá outras providências. Diário Oficial da União, 14 jan. 2005. Disponível em: www.in.gov.br. Acesso em: 14 jan. 2005. 
BRASIL. PRESIDÊNCIA DA REPÚBLICA. Lei $n^{\circ} 9.532$ - 10 dez. 1997. Altera a legislação tributária e dá outras providências. Diário Oficial da União, 11 dez. 1997. Disponível em: www.advocaciasantos.com.br/lei_9532_97.htm. Acesso em: 07 jan. 2005.

CARVALHO, Cristina H. A., LOPREATO, Francisco L. C. Finanças públicas, renúncia fiscal e o Prouni no governo Lula Impulso, Piracicaba, v. 16, n. 40, p. 93-104, maio-ago. 2005.

CATANI, Afrânio M.; GILIOLI, Renato de S. P. O Prouni na encruzilhada: entre a cidadania e a privatização. Linhas Críticas, Brasília, v. 11, n. 20, jan.-jun. 2005, p. 55-65.

CONSTANTINO, Luciana. MEC reforça auxílio a bolsistas carentes. Folha de S. Paulo, 26 jan. 2005a, "Cotidiano", p. C5.

. MEC vai anunciar "pacote de bondades" Folha Online, 13 jun. 2005b. Disponível em: www1.folha.uol.com.br/folha/educacao/ult305u17558.shtml. Acesso em: 16 maio 2006.

FOLHA DE S. PAULO. MEC quer criar controle do Prouni, 21 set. 2004a.

Programa de bolsa do governo federal seleciona 26,62\% dos candidatos Folha de S. Paulo, 21 dez. 2004b. Disponível em: www1.folha.uol.com.br/folha/educacao/ ult305u16758.shtml. Acesso em: 16 maio 2006.

Estudantes reclamam de não conseguir transferência de turma Folha de S. Paulo, 21 maio 2006, "Fovest". Disponível em: www1.folha.uol.com.br/fsp/fovest/ fo2105200604.htm. Acesso em 16 maio 2006.

FOLHA ONLINE. Universidades particulares pedem alteração em reserva de vagas Folha Online, 12 ago. 2004a, "Educação". Disponível em: www1.folha.uol.com.br/folha/ educacao/ult305u15930.shtml. Acesso em 16 maio 2006.

. MEC vai fiscalizar universidades participantes do Prouni Folha Online, 23 set. 2004b, "Educação". Disponível em: www1.folha.uol.com.br/folha/educacao/ ult305u16099.shtml. Acesso em: 16 maio 2006.

Estácio anuncia adesão ao Prouni e deixa de ser filantrópica Folha Online, 01 out. 2004c, "Educação". Disponível em: www1.folha.uol.com.br/folha/educacao/ ult305u16160.shtml. Acesso em: 16 maio 2006.

. Inscrições no ProUni superaram expectativas, diz Ministério da Educação Folha Online, 07 jan. 2006a, "Educação". Disponível em: www1.folha.uol.com.br/folha/ educacao/ult305u18224.shtml. Acesso em: 16 maio 2006.

. ProUni ocupa 98,8\% das mais de 91 mil bolsas oferecidas Folha Online, 17 jan. 2006b, "Educação". Disponível em: www1.folha.uol.com.br/folha/educacao/ ult305u18272.shtml. Acesso em: 16 maio 2006.

GOIS, Antônio. Estudo indica que bolsa não garante aluno na faculdade Folha de $S$. Paulo, 27 dez. 2004a, "Cotidiano". Disponível em: www1.folha.uol.com.br/folha/ educacao/ult305u16766.shtml. Acesso em: 16 maio 2006. 
CATANI, A. M.; HEY, A. P.; GILIOLI, R. S. P. PROUNI: Democratização do acesso...

“Quase desisti”, afirma estudante carente do Rio Folha de S. Paulo, 27 dez. 2004b, "Cotidiano", www1.folha.uol.com.br/folha/educacao/ult305u16767.shtml. Acesso em: 08 fev. 2005.

HADDAD, Fernando; BACHUR, João Paulo. Um passo atrás, dois à frente Folha de S. Paulo, 11 dez. 2004, "Tendências/Debates". Disponível em: www1.folha.uol.com.br/ fsp/opiniao/fz1112200409.htm. Acesso em: 05 jan. 2005.

MANCEBO, Deise. "Universidade para todos": a privatização em questão Pro-Posições, v. 15, n. 3 (45), set.-dez. 2004, p. 75-90.

MENA, Fernanda. Pareceres da FGV e de consultoria divergem sobre número de vagas Folha de S. Paulo, 17 dez. 2004, "Cotidiano". Disponível em www1.folha.uol.com.br/ folha/educacao/ult305u16741.shtml. Acesso em: 05 jan. 2005.

O ESTADO DE S. PAULO. Particulares reagem com mudanças no Prouni $O$ Estado de S. Paulo, 13 maio 2004, "Educando". Disponível em: www.estadao.com.br/educando/ noticias/2004/mai/27/103.htm. Acesso em: 6 out. 2005.

PUC MINAS. Bolsistas do Prouni têm bom desempenho na PUC Minas Jornal PUC Minas, 13 mar. 2006. Disponível em: www.universiabrasil.net/materia/ materia.jsp?materia=10300. Acesso em: 6 maio 2006.

SILVA JR., João dos Reis; CATANI, Afrânio. Com a bola quadrada Reportagem - Revista da Oficina de Informações, ano v, v. 56, maio 2004, p. 43-45.

SOUZA, Josias de. Medida provisória do Prouni cria o "promamata". Folha de S. Paulo, 26 set. 2004, p. 14A, "Brasil".

STACHUK, Mayra. MP criará loteria para ajudar aluno no ensino superior. Folha de S. Paulo, 31 ago. 2004, “Cotidiano". Disponível em: www1.folha.uol.com.br/folha/educacao/ ult305u16007.shtml. Acesso em: 16 out. 2005.

TAKAHASHI, Fábio. Prouni pode ter meia bolsa e vestibular a beneficiados Folha Online, 01 jul. 2004, "Educação". Disponível em: www1.folha.uol.com.br/folha/educacao/ ult305u15709.shtml. Acesso em: 12 dez. 2005.

UOL Educação. Comissão Nacional de Acompanhamento e Controle Social do Prouni toma posse UOL Educação, fev. 2006 “Educação" Disponível em: www.2.uol.com.br/ estudantenet/home2/educacao_fev_2006/m_2269.html. Acesso em: 15 maio 2006.

VALENTE, Ivan; HELENE, Otaviano. O Prouni e os muitos enganos Folha de S. Paulo. 11 dez. 2004, “Tendências/Debates". Disponível em: www1.folha.uol.com.br/fsp/opiniao/ fz1112200410.htm. Acesso em: 05 jan. 2005.

Texto recebido em 04 maio 2006

Texto aprovado em 08 jun. 2006 